\title{
Modeling Metal Influence on the Gate Opening in ZIF-8 Materials
}

\author{
Jenny G. Vitillo* and Laura Gagliardi
}

Cite This: Chem. Mater. 2021, 33, 4465-4473

Read Online

ABSTRACT: Zeolitic imidazolate frameworks (ZIFs) undergo pressure-induced phase transitions that are peculiar to each ZIF. The phase transition is associated with the rotation of the imidazolate, and it is accompanied by an increase of their pore openings, affecting ZIFs performance in separation processes. This phenomenon is known as the gate opening or the swing effect. Here we report the metal dependence of the ambient pressure and high pressure (HP) phases of ZIF- $8(\mathrm{M})$ with $\mathrm{M}=\mathrm{Mg}, \mathrm{Fe}$, and $\mathrm{Zn}$, determined by using periodic Kohn-Sham density functional models. We show that the substitution of $\mathrm{Zn}$ with $\mathrm{Mg}$ or $\mathrm{Fe}$ has a big influence on the gate opening energy, which significantly decreases, an opposite trend than what was previously reported upon functionalization of the linker. The lowest energy phase of

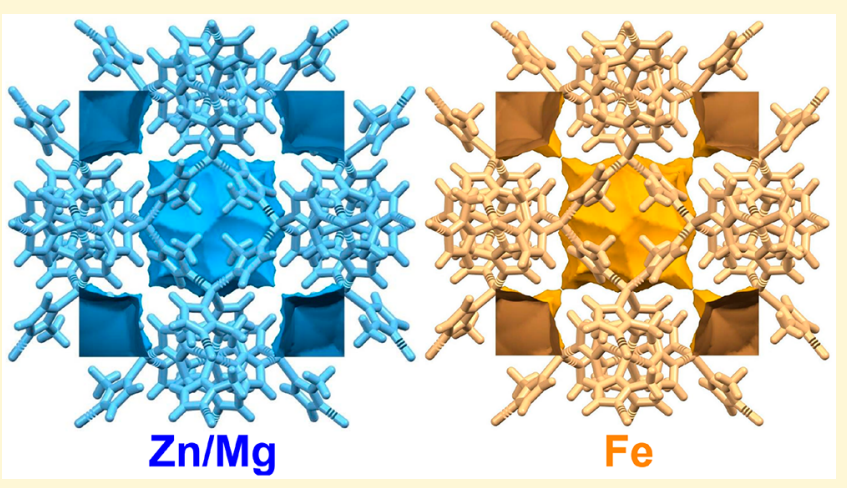
ZIF- $8(\mathrm{Fe})$ is different than for ZIF- $8(\mathrm{Mg})$ and ZIF- $8(\mathrm{Zn})$, and its structure is significantly closer to the HP phase. Multireference wave function methods have been used to study the electronic structure of ZIF-8( $\mathrm{Fe})$, confirming the metal center to be high spin $(S$ $=2$ ) divalent iron in antiferromagnetic coupling. The high-spin nature of the iron species coupled with a band gap in the visible light range makes ZIF-8(Fe) an interesting material for catalysis and photocatalysis.

\section{INTRODUCTION}

Zeolitic imidazolate frameworks (ZIFs) are a class of materials whose structure is obtained by connecting unitary metal centers through organic molecules containing imidazolate rings. ${ }^{1-3}$ The bond between the metal and a nitrogen atom on the imidazolate ring gives these materials a significant thermal, mechanical, and chemical stability. ${ }^{3-6}$ This, together with their porous nature, places them among the most studied materials for various applications and in particular for the separation of both gases and liquids ${ }^{7-10}$ as well as for catalysis. ${ }^{11,12}$ The ZIF$8\left(\mathrm{Zn}(\mathrm{mIm})_{2}, \mathrm{mIm}=\text { methylimidazolate }\right)^{3,7,8,13}$ material has been extensively investigated. Its porous structure is constituted by spherical micropores (diameter of $11.6 \AA$ ) connected through four-membered (4MR) and six-membered rings $(6 \mathrm{MR})$. In its ambient pressure phase (ZIF-8(Zn)-AP, see Figure $1 \mathrm{~b})$, these openings are quite small, having a diameter of just 0.8 and $3.0 \AA$, respectively. ${ }^{7,8}$ These small openings would make in principle ZIF-8(Zn) a molecular sieve for small gas molecules with similar radius such as $\mathrm{H}_{2} / \mathrm{CH}_{4}$. However, ZIF-8 has a structural flexibility that makes challenging its use as molecular sieve. Increasing the fluid pressure induces a phase transition, associated with the rotation of the imidazolate rings: ${ }^{7,14-16}$ the angle $\theta$ between the imidazole ring and the $4 \mathrm{MR}$ window (see Figure 1a) increases from $\sim 65^{\circ}$ to $\sim 85^{\circ}$. The pressure associated with the phase transition strongly depends on the fluid and on the temperature: for example, for $\mathrm{N}_{2}$ at $77 \mathrm{~K}$, the transition starts at 0.0002 bar, $^{15}$ while for $\mathrm{O}_{2}$ at $90 \mathrm{~K}$ is observed above 5000 bar. ${ }^{8}$ This high pressure phase (ZIF-8(Zn)-HP, see Figure 1d) shows a decreased separation ability due to the increase of the diameter of the $4 \mathrm{MR}$ and $6 \mathrm{MR}$ to 2.2 and $3.6 \AA$, respectively ("gate opening" or "swing effect" phenomenon). 8,17 The understanding of the role of ZIFs building blocks (the metal and the linker) on the framework flexibility is pivotal for directing ZIFs adsorption performances. ${ }^{15}$ Hobday et al. have studied how to tune the gate opening phenomena by changing the substituents on the imidazolate rings. ${ }^{7}$ In this study, we employ periodic Kohn-Sham density functional methods (KSDFT) to explore the metal substitution effect on the structural flexibility of ZIF-8. Among the isostructural analogues reported so far for ZIF-8, we considered the magnesium ${ }^{18}$ and the iron analogue (also knowns as MUV-3). ${ }^{19}$ Previous magnetic measurements ${ }^{19}$ indicate the divalent iron centers in ZIF$8(\mathrm{Fe})$ to be in high spin, a characteristic that would make this material particularly suitable as a catalyst for $\mathrm{C}-\mathrm{H}$ bond scission. Multireference wave function-based methods have been used to model ZIF- $8(\mathrm{Fe})$ with the aim to characterize the electronic structure of iron centers.

Received: February 22, 2021

Revised: April 12, 2021

Published: April 21, 2021 


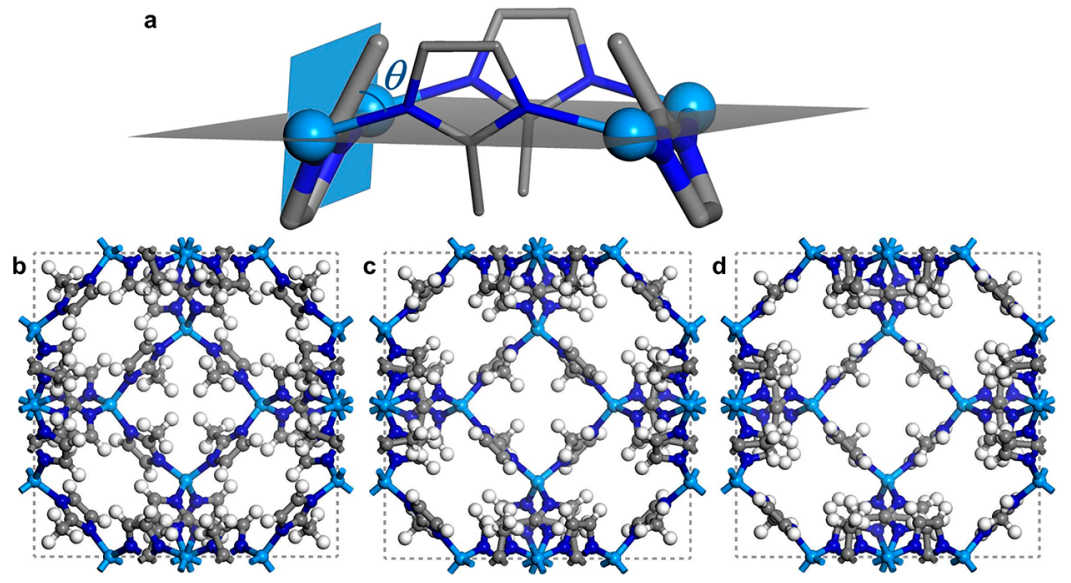

Figure 1. Definition of the angle $\theta$ is the same used in previous works: ${ }^{7,8}$ (a) $\theta$ is the angle between the plane of the imidazolate (Im) ring (light blue) and the 4MR plane (gray). Three different phases of ZIF-8 can be identified, differing on $\theta$ : (b) ZIF-8-AP $\left(\theta \sim 65^{\circ}\right)$, (c) ZIF-8-IP $\left(\theta \sim 75^{\circ}\right)$, and (d) ZIF-8-HP $\left(\theta \sim 85^{\circ}\right)$. View along [001]. Color code of the atoms: metal (light blue), $\mathrm{N}$ (blue), C (gray), and $\mathrm{H}$ (white). In (a), all the $\mathrm{H}$ atoms are omitted for clarity.

\section{COMPUTATIONAL METHODS}

2.1. Periodic Models. All the calculations were performed by using the CRYSTAL17 program. ${ }^{20}$ The crystallographic cells used in the calculations contain 12 formula units $\left(\mathrm{M}_{12} \mathrm{C}_{96} \mathrm{H}_{120} \mathrm{~N}_{48}\right)$ and have a cubic lattice with space group $I \overline{4} 3 M$. For the iron system, the optimization was performed by considering a total spin $S=24,12$, and 0 , respectively, corresponding to a spin on each iron of $S=2,1$, and 0 , respectively.

To study the broken symmetry solution of the singlet state for ZIF$8(\mathrm{Fe})$, corresponding to $S=2$ iron centers in antiferromagnetic coupling, the space group was reduced to $P \overline{4} 3 M$. Lattice parameters and atom positions were fully optimized by keeping fixed the initial space group. A first set of structures was optimized without imposing any geometrical constraints and using as starting structures the experimental structures of ZIF-8(Zn)-AP (see Figure 1b) and ZIF$8(\mathrm{Zn})$-HP (see Figure $1 \mathrm{~d}){ }^{8}$ The structures of the AP and HP phases for $\mathrm{Mg}$ and $\mathrm{Fe}$ have not yet been experimentally reported (see the discussion in sections 3.2 and 3.3 for further details). We thus started their structure optimization from the ZIF- $8(\mathrm{Zn})-\mathrm{AP}$ and ZIF- $8(\mathrm{Zn})$ $\mathrm{HP}$ structures and replaced $\mathrm{Zn}$ with $\mathrm{Mg}$ or $\mathrm{Fe}$. A second set of structures was optimized from the experimental ZIF-8(Zn)-AP, ${ }^{8} \mathrm{ZIF}-$ $8(\mathrm{Zn})-\mathrm{HP},{ }^{8}$ and $\mathrm{ZIF}-8(\mathrm{Fe})^{19}$ cells upon metal substitution by fixing the dihedral angles involved in the rotation of the $\mathrm{mIm}$ rings $(\mathrm{mIm}=$ 2-methylimidazole). The Becke's three-parameter hybrid exchange functional $^{21}$ was used supplemented with the Lee, Yang, and Parr's gradient-corrected correlation functional ${ }^{22}$ in their unrestricted formalism and corrected with the scheme to include the long-range dispersion interaction proposed by Grimme ${ }^{23}$ and by Civalleri et al. (hereafter B3LYP-D*). ${ }^{24}$ For the iron-based ZIF, the optimization was performed also employing PBEO-D* and the Minnesota functional M06- $\mathrm{L}^{25}$ to verify that all functionals predict the same electronic structure. For the $\mathrm{Fe}, \mathrm{Zn}$, and $\mathrm{Mg}$ atoms, the PeintingerOliveira-Bredow basis set was used (pob-TZVP) ${ }^{26}$ while for the other atoms all-electron Gaussian-type basis sets of triple- $\zeta$ valence quality were adopted (TZV for $\mathrm{C}, \mathrm{N}$, and $\mathrm{H}){ }^{27,28}$

For numerical integration of the exchange-correlation term, a (75 974) pruned grid was adopted for the B3LYP-D* and PBE0-D3 calculations, while a $(99,1454)$ was used for M06-L. ${ }^{29}$ The threshold conditions for convergence in the self-consistent field (SCF) iterative procedure was set to $10^{-8}$ hartree. The Pack-Monkhorst/Gilat shrinking factors for the reciprocal space were set to 6 , corresponding to 16 points at which the Hamiltonian matrix was diagonalized. Five truncation criteria for the two-electron integrals were set to $7,7,7,7$, and 16 (the first two values referred to the Coulomb series, while the last three values to the HF exchange series, TOLINTEG keyword). ${ }^{20}$ To accelerate the convergence in the SCF process, a modified Broyden's scheme, ${ }^{30}$ following the method proposed by Johnson, ${ }^{31}$ was adopted. The method was applied after five SCF iterations, with $30 \%$ mixing of the Fock/Kohn-Sham (KS) matrices and the Johnson's parameter set to 0.05 . The above computational parameters ensured full numerical convergence of all computed properties described herein. The electronic band structure and the density of states plots were obtained by using CRYSPLOT. ${ }^{32}$ The electrostatic potential maps were visualized by the J-ICE online viewer. ${ }^{33}$

2.2. Multireference Wave Function-Based Calculations. Mono- and di-iron clusters $\left(\mathrm{Fe}_{1}\right.$ and $\mathrm{Fe}_{2}$ clusters, respectively, see Figure S6) were carved from the high spin structure of ZIF-8 $(\mathrm{Fe})$ optimized without constraints at the B3LYP-D* level. The dangling bonds were saturated with $\mathrm{H}$ atoms whose position was optimized by using the Gaussian 16 program, ${ }^{34}$ the B3LYP-D3 functional, ${ }^{21-23}$ and all-electron Gaussian-type basis sets of triple- $\zeta$ valence quality (TZVp). ${ }^{27,28}$

Single-point multireference wave function-based calculations on the mono-iron $\left(\mathrm{Fe}_{1}\right)$ and di-iron $\left(\mathrm{Fe}_{2}\right)$ clusters were performed by using the complete active space self-consistent field (CASSCF) $)^{35}$ method followed by perturbation theory to second order (CASPT2) ${ }^{36}$ as implemented in the Molcas 8.2 program. ${ }^{37}$ Relativistic all-electron ANO-RCC basis sets were used for all the atoms. ${ }^{38,39}$ For the $\mathrm{Fe}_{1}$ cluster, the calculations were performed adopting triple- $\zeta$ quality basis sets for $\mathrm{N}$ and $\mathrm{Fe}$ atoms and double- $\zeta$ quality for $\mathrm{C}$ and $\mathrm{H}$. Because for $\mathrm{Fe}_{2}$ such a basis set was not affordable, a smaller basis set was used, composed of triple- $\zeta$ quality for $\mathrm{Fe}$, double- $\zeta$ quality for $\mathrm{N}$, and a minimal basis set for $\mathrm{C}$ and $\mathrm{H}$. This basis was also used for $\mathrm{Fe}_{1}$ to assess the dependence of spin state stability on the basis set.

The resolution of identity combined with the Cholesky decomposition was used to reduce the cost associated with the calculation of the two-electron integrals. ${ }^{40}$ No symmetric constraints were imposed in the calculation. The active space includes all the molecular orbitals having the main contribution from the $3 \mathrm{~d}$ orbitals of the $\mathrm{Fe}$ centers and their valence electrons. $\mathrm{For} \mathrm{Fe}_{1}$, the active space included 4 electrons and 5 orbitals $(4,5)$, while for $\mathrm{Fe}_{2}$ it included 8 electrons in 10 orbitals $(8,10)$. The convergence with the active space size was explored considering $(4,10)$ and $(8,20)$ as active spaces for $\mathrm{Fe}_{1}$ and $\mathrm{Fe}_{2}$, respectively. The CASPT2 relative stability of the quintet, triplet, and singlet states for $\mathrm{Fe}_{1}$ does not vary significantly with the basis set (see Tables S1 and S2 as well as section S2 in the Supporting Information for the discussion). This trend validates the use of a smaller basis set for $\mathrm{Fe}_{2}$.

\section{RESULTS}

3.1. ZIF-8(Zn). The optimization without geometrical constraints of the ZIF- $8(\mathrm{Zn})$ structures resulted in the AP phase, independently of the phase used as guess structure. This 
Table 1. Geometry and Energy Relevant Parameters for All the Optimized ZIF-8(M) Structures ( $M=\mathrm{Mg}, \mathrm{Zn}, \mathrm{Fe}$; Cell Formula: $\mathrm{M}_{12} \mathrm{C}_{96} \mathrm{H}_{120} \mathrm{~N}_{48}$ ) at the B3LYP-D*/TZVp Level Using Different Geometrical Constraints ${ }^{a}$

\begin{tabular}{|c|c|c|c|c|c|c|c|c|c|c|c|c|}
\hline M & $2 S+1$ & phase & method $^{b}$ & $\theta^{c}$ & $a$ & $V$ & $d(\mathrm{M}-\mathrm{N})$ & $\phi(4 \mathrm{MR})^{d}$ & $\phi(6 \mathrm{MR})^{d}$ & $\Delta E$ & band gap & $\Delta V(\%)$ \\
\hline \multirow[t]{5}{*}{$\mathrm{Mg}$} & 1 & $\mathrm{AP}$ & B3LYP, free & 66.9 & 17.272 & 5152.9 & 2.053 & 0.7 & 3.0 & 0.0 & 6.29 & 0.0 \\
\hline & 1 & IP & B3LYP, fix & 74.4 & 17.212 & 5098.8 & 2.054 & 1.0 & 3.1 & 11.4 & 6.26 & -1.1 \\
\hline & 1 & IP-A & B3LYP, fix & 75.6 & 17.330 & 5205.1 & 2.056 & 1.9 & 3.3 & 28.0 & 6.20 & 1.0 \\
\hline & 1 & $\mathrm{HP}$ & B3LYP, fix & 89.3 & 17.339 & 5212.8 & 2.059 & 1.8 & 3.7 & 93.4 & 6.46 & 1.1 \\
\hline & 1 & & expt, $\mathrm{RT}^{18}$ & & $17.28(5)$ & 5159.8 & & & & & & \\
\hline \multirow[t]{6}{*}{$\mathrm{Zn}$} & 1 & $\mathrm{AP}$ & B3LYP, free & 64.4 & 17.003 & 4915.6 & 1.998 & 0.6 & 3.0 & 0.0 & 6.34 & 0.0 \\
\hline & 1 & IP & B3LYP, fix & 74.4 & 16.937 & 4858.2 & 1.999 & 0.9 & 3.0 & 24.7 & 6.30 & -1.2 \\
\hline & 1 & IP-A & B3LYP, fix & 75.0 & 17.038 & 4946.0 & 2.001 & 1.7 & 3.2 & 44.0 & 6.29 & 0.6 \\
\hline & 1 & $\mathrm{HP}$ & B3LYP, fix & 89.6 & 17.030 & 4938.9 & 2.003 & 1.7 & 3.6 & 138.4 & 6.46 & 0.5 \\
\hline & 1 & $\mathrm{AP}$ & $\mathrm{XRD}, 77-112 \mathrm{~K}^{8}$ & 65.9 & 17.013 & 4924.5 & 1.992 & 0.8 & 3.0 & & & \\
\hline & 1 & $\mathrm{HP}$ & $\mathrm{XRD}, 112 \mathrm{~K}, 7000 \mathrm{bar}, \mathrm{CH}_{4}^{8}$ & 89.2 & 17.172 & 5063.8 & 2.006 & 2.3 & 3.7 & & & 2.8 \\
\hline \multirow[t]{9}{*}{$\mathrm{Fe}$} & 49 & $\mathrm{AP}$ & B3LYP, fix & 66.0 & 17.293 & 5171.2 & 2.043 & 0.7 & 3.1 & 35.7 & 3.39 & 0.8 \\
\hline & 49 & IP & B3LYP, free & 79.9 & 17.249 & 5131.7 & 2.044 & 1.3 & 3.4 & 8.1 & 3.47 & 0.0 \\
\hline & 49 & IP-A & B3LYP, free & 73.9 & 17.317 & 5193.1 & 2.044 & 1.8 & 3.3 & 17.6 & 3.46 & 1.2 \\
\hline & 49 & IP & B3LYP, fix & 74.4 & 17.269 & 5150.0 & 2.043 & 1.0 & 3.3 & 11.2 & 3.46 & 0.4 \\
\hline & 49 & IP-A & B3LYP, fix & 74.8 & 17.305 & 5182.4 & 2.045 & 1.8 & 3.3 & 20.1 & 3.47 & 1.0 \\
\hline & 49 & $\mathrm{HP}$ & B3LYP, fix & 89.5 & 17.277 & 5156.9 & 2.047 & 1.7 & 3.7 & 64.9 & 3.46 & 0.5 \\
\hline & 1 (BS) & IP & B3LYP, free & 81.6 & 17.240 & 5124.2 & 2.044 & 1.3 & 3.5 & 0.0 & 3.73 & -0.1 \\
\hline & 1 (BS) & IP-A & B3LYP, free & 74.9 & 17.306 & 5182.8 & 2.044 & 1.8 & 3.4 & 9.4 & 3.69 & 1.0 \\
\hline & 1 (BS) & IP-A & $\mathrm{XRD}, \mathrm{RT}^{19}$ & 74.4 & 17.165 & 5058.0 & 2.048 & 1.6 & 3.0 & & & \\
\hline
\end{tabular}

${ }^{a}$ Angle between the imidazolate ring and $4 \mathrm{MR}$ window as defined in Figure 1a $\left(\theta\right.$, deg), cell size $(a, \AA)$, unit cell volume $\left(V, \AA^{3}\right)$, the metalnitrogen bond length $(d(\mathrm{M}-\mathrm{N})), \AA), 4 \mathrm{MR}$ window diameter $(\phi(4 \mathrm{MR}), \AA), 6 \mathrm{MR}$ window diameter $(\phi(6 \mathrm{MR}), \AA)$, difference in energy with respect to the ground state per crystallographic cell $\left(\Delta E, \mathrm{~kJ} \mathrm{~mol}^{-1}\right)$, band gap $(\mathrm{eV})$, percent change in unit cell volume $(\Delta V$, \%). AP and $\mathrm{HP}$ correspond to the ambient pressure and high pressure phase of ZIF- $8(\mathrm{Zn})$, respectively. IP and IP-A are structures showing intermediate values of $\theta$ compared to those typical of the AP and HP phases. IP-A corresponds to the ambient pressure phase reported for ZIF-8(Fe). ${ }^{19} \mathrm{IP}$ and IP-A differ in the orientation of the methyl groups (see Figure 2 and section 3.3). BS = broken symmetry solution. ${ }^{b}$ Free $=$ no geometrical constraints, fix $=$ fixed dihedral angles to the experimental values of ZIF-8(Zn)-HP for HP structures, of ZIF-8(Zn)-AP for AP structures, and of ZIF-8(Fe)-IP-A for IP structures. ${ }^{c}$ Determined by using Mercury 2020.2.0. ${ }^{42}{ }^{d}$ Diameters of $4 \mathrm{MR}$ and $6 \mathrm{MR}$ calculated by using the void analysis routine in Mercury 2020.2.0 (solvent accessible surface, grid spacing of $0.2 \AA$ ). Following the procedure used in the literature, ${ }^{7,8}$ the probe size was increased until the $4 \mathrm{MR}$ (or the $6 \mathrm{MR}$ ) windows were no longer accessible to solvent.

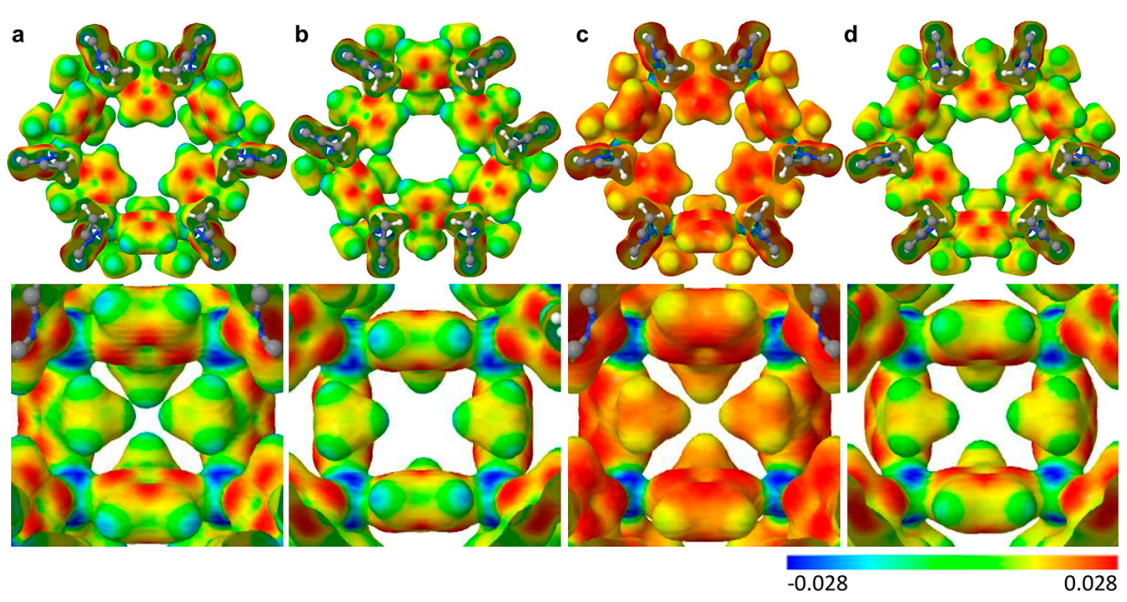

Figure 2. Electrostatic potential maps on (a) ZIF-8(Zn)-AP, (b) ZIF-8(Zn)-HP, (c) ZIF-8(Mg)-AP, and (d) ZIF-8(Fe)-IP calculated at the B3LYP-D* level and mapped on an electron charge density isosurface (0.003 e). Top view: 6MR openings. Bottom view: 4MR openings. Blue: positive values of the potential $\left(+0.028 \mathrm{e} \mathrm{bohr}^{-3}\right)$. Red: negative values $\left(-0.028 \mathrm{e} \mathrm{bohr}^{-3}\right)$. Green: neutral values. Color code of the atoms: metal (light blue), $\mathrm{N}$ (blue), $\mathrm{C}$ (gray), and $\mathrm{H}$ (white).

observation agrees with what reported by Hobday et al. ${ }^{8}$ that the AP phase is the most stable one. The optimization of ZIF$8(\mathrm{Zn})$ in its HP phase was obtained by fixing the dihedral angles responsible for the rotation of the imidazolates to the HP experimental values ${ }^{8}$ to avoid its minimization to the AP structure. The AP and HP phases present a similar cell volume, with the HP cell slightly expanded than the AP cell. This change is associated with a slight increase of the metal-N bond distance $(d(M-N)$, see Table 1$)$. The computed cell parameters match the experimental values for ZIF-8(Zn)-AP (see Table 1). For ZIF-8(Zn)-HP, it is not possible to make a comparison with the experimental values, because the single crystal structures were obtained only in the presence of adsorbates. ${ }^{7,8}$ Hobday et al. monitored the change in the ZIF$8(\mathrm{Zn})$ unit cell volume at increasing pressures of $\mathrm{N}_{2}, \mathrm{O}_{2}, \mathrm{Ar}$, and $\mathrm{CH}_{4}$. Their data show an increase of the cell volume upon 
the $\mathrm{AP} \rightarrow \mathrm{HP}$ phase transition. Moreover, the volume cell behavior of ZIF-8 upon pressure observed by Moggach et al. ${ }^{14}$ would suggest a larger cell volume for the HP phase.

The HP phase is predicted to be less stable than the AP phase for $\mathrm{Zn}$ (see Table 1), in agreement with experiments, showing that our models are a good representation of the experimental systems. Their energy difference $\left(\Delta E_{\mathrm{AP} \rightarrow \mathrm{HP}}\right)$ is computed to be $138.4 \mathrm{~kJ} \mathrm{~mol}^{-1}$ per unit cell, which is $5.8 \mathrm{~kJ}$ $\mathrm{mol}^{-1}$ linker $^{-1}$. This value is similar to the one reported previously $\left(5.3 \mathrm{~kJ} \mathrm{~mol}^{-1}\right.$ linker $\left.^{-1}\right){ }^{7}$

Both phases are predicted to be insulating materials (see Table 1 and parts a and b of Figure S1), with the top of the valence band and the bottom of the conduction band dominated by the electronic levels of the linker, as typical of closed-shell metal-organic frameworks (see Figures S1-S3). ${ }^{41}$

The electrostatic potential maps of the AP and HP phases are reported in Figures $2 \mathrm{a}$ and $2 \mathrm{~b}$, respectively. The two maps are very similar, with positive values of the potential mainly located around $\mathrm{Zn}$, while the negative values associated not only with the nitrogen atoms but also with the $\mathrm{C}-\mathrm{C}$ bond of the imidazolate ring. These maps show the increased accessibility of the $6 \mathrm{MR}$ (top) and $4 \mathrm{MR}$ openings (bottom) because of the AP $\rightarrow$ HP phase transition. The $4 \mathrm{MR}$ diameter in AP and HP phases is reported in Table 1.

3.2. ZIF-8(Mg). The available diffraction data for ZIF$8(\mathrm{Mg})$ include the cell parameters but they do not include the atom coordinates. ${ }^{18}$ From the experimental data it is then not possible to know if the ambient pressure phase of the ZIF$8(\mathrm{Mg})$ is $\mathrm{AP}$ or HP. Moreover, the change in the volume cell upon pressure has not been studied for ZIF- $8(\mathrm{Mg})$. The present calculations indicate $\mathrm{AP}$ as the most stable $\mathrm{ZIF}-8(\mathrm{Mg})$ phase, like for ZIF-8(Zn). The optimization without geometry constraints resulted in the AP phase $\left(\theta \sim 65^{\circ}\right)$, independently of the starting geometry. The AP to $\mathrm{HP}$ transition involves a cell expansion larger than that obtained for the $\mathrm{Zn}$ analogous (see Table 1). Unlike ZIF-8(Zn), here the AP $\rightarrow$ HP transition would require only $93.4 \mathrm{~kJ} \mathrm{~mol}^{-1}\left(3.9 \mathrm{~kJ} \mathrm{~mol}^{-1}\right.$ linker $\left.{ }^{-1}\right)$. This smaller value of the energy required for the gate opening than ZIF- $8(\mathrm{Zn})$ can be associated with the larger $d(\mathrm{M}-\mathrm{N})$ for $\mathrm{Mg}$ than for $\mathrm{Zn}$ (2.053 vs $1.998 \AA$ ).

The electrostatic potential map of ZIF- $8(\mathrm{Mg})$ indicates a more polar material than its zinc analogue (compare parts a and $c$ of Figure 2). This is similar to what reported for other metal-organic framework series. ${ }^{43}$ Experimentally, Horike et al. ${ }^{18}$ reported a larger $\mathrm{CO}_{2}$ capacity in ZIF- $8(\mathrm{Mg})$ than in ZIF$8(\mathrm{Zn})$ per formula unit, which can be attributed to a larger affinity of $\mathrm{CO}_{2}$ for magnesium-based ZIF: a more polar surface can explain the larger $\mathrm{CO}_{2}$ uptake by $\mathrm{ZIF}-8(\mathrm{Mg})$.

Band gap calculations indicate that $\mathrm{ZIF}-8(\mathrm{Mg})$ is an insulator (see Figure S1 and Table 1). This is not surprising for a closed-shell material, in which the electronic levels determining the band gap are mainly associated with the molecular orbitals of the linker (see Figure S4).

3.3. ZIF-8(Fe). A close examination of the experimental structure of ZIF- $8(\mathrm{Fe})$ at ambient pressure ${ }^{19}$ shows that it differs from both the AP and HP phases of ZIF- $8(\mathrm{Zn})$. The angle $\theta$ between the imidazole ring and the $4 \mathrm{MR}$ window (see Figure 1a) lies between the typical AP $\left(\theta \sim 65^{\circ}\right)$ and HP $(\theta \sim$ $85^{\circ}$ ) values. We indicate this intermediate phase as IP (see Figure 1c). Another difference between the ZIF-8( $\mathrm{Zn})$ and ZIF-8 $(\mathrm{Fe})$ experimental structures is the position of the $\mathrm{H}$ atoms of the methyl groups. In ZIF- $8(\mathrm{Zn})$, only one $\mathrm{H}$ per methyl is pointing toward the $4 \mathrm{MR}$ openings (see Figure $4 \mathrm{a}$ ).

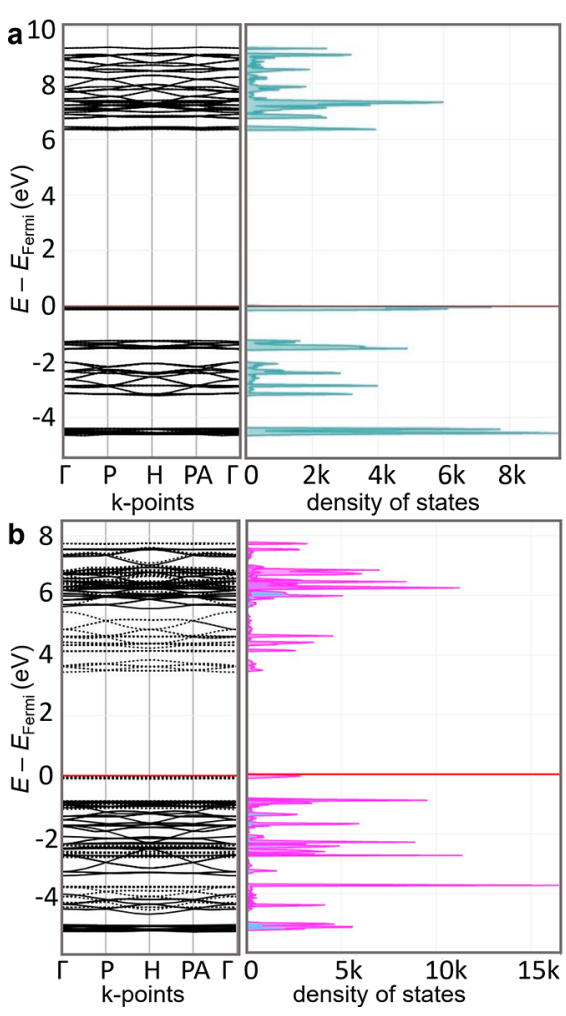

Figure 3. Electronic band structure and density of states (DOS) of (a) ZIF-8(Zn)-AP and (b) ZIF-8(Fe)-IP $(2 S+1=49)$ obtained at the B3LYP-D*/TZVp level. In (b), blue and pink areas correspond to alpha and beta electrons, respectively.

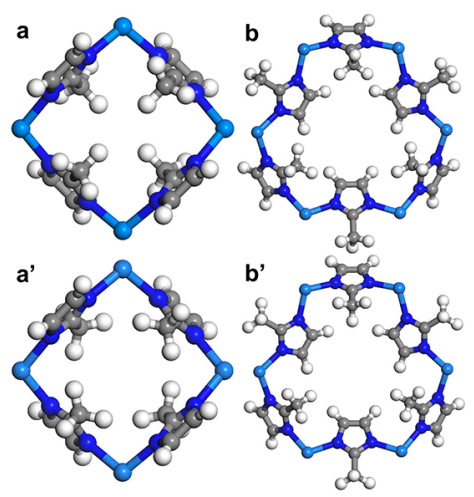

Figure 4. $4 \mathrm{MR}$ and $6 \mathrm{MR}$ openings in (a, b) ZIF-8-IP and $\left(\mathrm{a}^{\prime}, \mathrm{b}^{\prime}\right)$ ZIF-8-IP-A, respectively. Color code of the atoms: metal (light blue), $\mathrm{N}$ (blue), $\mathrm{C}$ (gray), and $\mathrm{H}$ (white).

In ZIF-8 $(\mathrm{Fe})$, two hydrogens on each methyl are pointing toward the 4MR windows (Figure 4a'). We will indicate this structure as IP-A (compare also the 6MR windows of IP and IP-A in Figures $4 b$ and $4 b^{\prime}$, respectively). ZIF- 8 pores are so small that any change in the structure has a big impact on the pore dimension and thus on its separation properties. The different orientation of the methyl in IP and IP-A modifies the diameter of both $4 \mathrm{MR}$ and $6 \mathrm{MR}$ windows (see data in Table 1 as well as Figures $2 \mathrm{~d}$ and 5 ). Because the position of the $\mathrm{H}$ atoms is not detected by $\mathrm{XRD}$, we investigated the relative stability of the IP and IP-A conformers to try to understand which of these phases is more likely.

The phase of the fully optimized ZIF- $8(\mathrm{Fe})$ structure is different for different spin states of the iron centers. For high- 


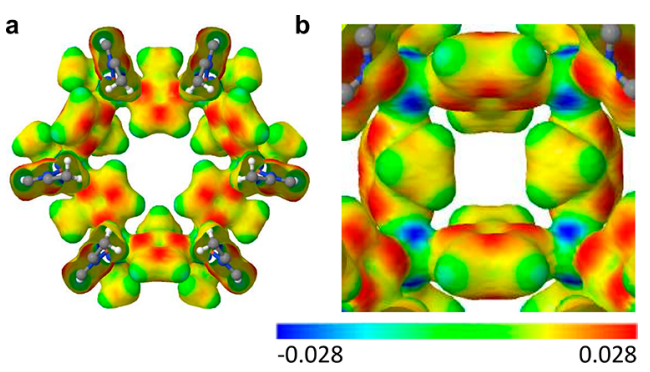

Figure 5. Electrostatic potential maps on ZIF-8( $\mathrm{Fe})-\mathrm{IP}-\mathrm{A}$ computed at the B3LYP-D*/TZVp level as mapped on an electron charge density isosurface (0.003 e). (a) 6MR openings. (b) 4MR openings. Blue: positive values of the potential $\left(+0.028 \mathrm{e} \mathrm{bohr}^{-3}\right)$. Red: negative values $\left(-0.028 \mathrm{e} \mathrm{bohr}^{-3}\right)$. Green: neutral values. Color code of the atoms: metal (light blue), $\mathrm{N}$ (blue), $\mathrm{C}$ (gray), and $\mathrm{H}$ (white).

spin Fe centers (corresponding to $2 S+1=49$ and the broken symmetry solution for $2 S+1=0$ ), the most stable phase is the IP phase, while it is AP for lower-spin values $(2 S+1=12$ and 0 ) (see Tables 1 and 2). The data in Table 2 point to a direct

Table 2. Geometry and Energy Relevant Parameters for Periodic ZIF-8(Fe) Models (Cell Formula: $\mathrm{Fe}_{12} \mathrm{C}_{96} \mathrm{H}_{120} \mathrm{~N}_{48}$ ) Optimized without Geometrical Constraints Using Different DFT Methods and Considering Different Spin Multiplicities $(2 S+1)^{a}$

\begin{tabular}{cllccrr} 
DFT-D $^{*}$ & $2 S+1$ & phase & $\theta$ & $a$ & \multicolumn{1}{c}{$V$} & \multicolumn{1}{c}{$\Delta E$} \\
B3LYP-D* $^{*}$ & 49 & IP & 79.9 & 17.249 & 5131.7 & 8.1 \\
& 25 & AP & 65.6 & 17.010 & 4921.4 & 2408.6 \\
& $1(\mathrm{LS})$ & AP & 65.5 & 16.843 & 4777.9 & 3151.3 \\
& $1(\mathrm{BS})$ & IP & 81.6 & 17.240 & 5124.2 & 0.0 \\
PBE0-D* & 49 & IP & 80.4 & 17.186 & 5076.1 & 6.6 \\
& 25 & AP & 67.2 & 16.942 & 4862.9 & 2912.7 \\
& $1(\mathrm{LS})$ & AP & 66.0 & 16.776 & 4721.5 & 3651.2 \\
& $1(\mathrm{BS})$ & IP & 81.1 & 17.187 & 5077.2 & 0.0 \\
M06-L & 49 & IP & 75.4 & 17.203 & 5091.0 & 6.9 \\
& $1(\mathrm{LS})^{b}$ & AP & 65.7 & 16.744 & 4694.7 & 3417.4 \\
& $1(\mathrm{BS})$ & IP & 76.3 & 17.183 & 5073.6 & 0.0
\end{tabular}

${ }^{a}$ Angle between the imidazolate ring and $4 \mathrm{MR}$ window as defined in Figure 1a $(\theta, \operatorname{deg})$, cell size $(a, \AA)$, unit cell volume $\left(V, \AA^{3}\right)$, and difference in energy with respect to the ground state per crystallographic cell $\left(\Delta E, \mathrm{~kJ} \mathrm{~mol}^{-1}\right)$. BS = broken symmetry solution. $\mathrm{LS}=$ low spin. ${ }^{b}$ Restricted formalism.

dependence of $\theta$ on the spin of the iron centers, with the IP-A conformer calculated to be less stable than the IP conformer (see Table 1). This is verified not only for iron but also for $\mathrm{Zn}$ and Mg-based materials. Nevertheless, the calculated ZIF$8(\mathrm{Fe})-\mathrm{IP}-\mathrm{A}$ structure is the closest to the experimental structure reported by López-Cabrelles et al. ${ }^{19}$ in terms of $\theta$.

All the density functional results indicate that the iron centers are high spin in ZIF-8(Fe) (spin state $S=2$ for each iron center), while the lowest spin states are significantly higher in energy (see Table 2): $S=1\left(\Delta E \sim 200 \mathrm{~kJ} \mathrm{~mol}^{-1}\right.$ higher per iron center $)$ and $S=0\left(\Delta E \sim 500 \mathrm{~kJ} \mathrm{~mol}^{-1}\right.$ higher per iron center). We have performed multireference calculations for ZIF-8(Fe) using mono- and di-iron clusters to benchmark the relative stability of the different spin states obtained by all the DFT methods adopted in this work (B3LYP, M06-L, and PBE0). The mono-iron cluster allows us to estimate the relative stability of each spin state for a single iron center. The multireference calculations (see Tables S1 and
S2) agree with the spin order predicted by the DFT methods: $S=2<1<0$. The di-iron cluster is a model of how the electronic configuration of each iron center is influenced by the presence of a vicinal iron. The results obtained with the di-iron cluster indicate that all the spin states $(2 S+1=9,7,5,3$, and 1) correspond to eight unpaired electrons in the $3 \mathrm{~d} F e$ orbitals (see Figure 6 and Table S3; for more details on multireference

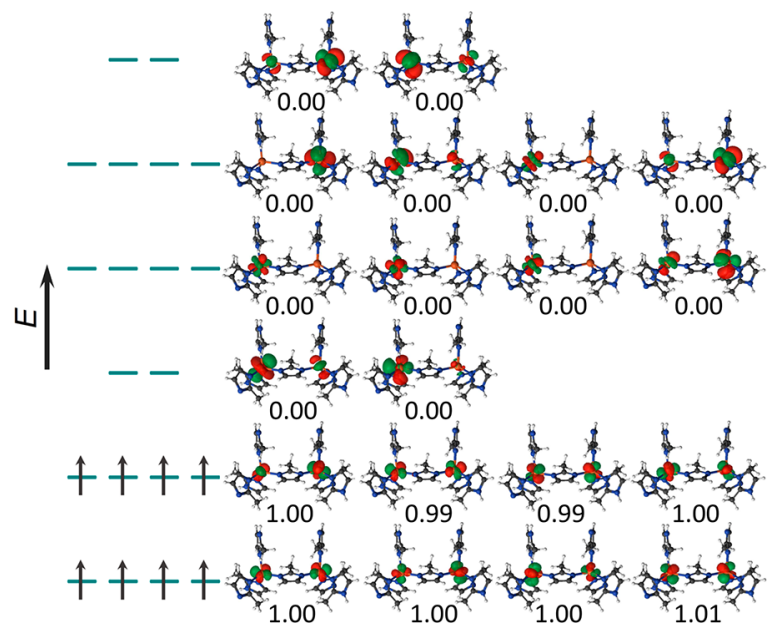

Figure 6. Qualitative molecular orbital diagram showing the natural orbitals for the di-iron cluster $\mathrm{Fe}_{2}$ obtained at the $\operatorname{CASSCF}(8,20)$ level for $S=0$. For each orbital, it is indicated the occupancy. Color code of the atoms: iron (orange), $\mathrm{N}$ (blue), $\mathrm{C}$ (gray), and $\mathrm{H}$ (white). Positive values of the orbitals are in red negative values in green.

calculations see section S2). The spin states lower than 4 show a substantial multireference character, each of them resulting from the linear combination of several electronic configurations having similar configuration interaction (CI) coefficients. All the computed spin states differ by $1.0 \mathrm{~kJ} \mathrm{~mol}^{-1}$ per iron center at most, according to both CASSCF and CASPT2 (see Table S3). CASPT2 calculations using a $(8,20)$ active space predict the high spin state and the open-shell singlet to be degenerate and to be the most stable ones (see Table S3). Again, multireference results agree with the DFT calculations: for the periodic model of ZIF-8, all the DFT methods considered predict the highest-spin state $(2 S+1=$ 49 ) and the broken-symmetry solution (BS) for the singlet (2S $+1=1$ ) as the most stable electronic configurations (see Table 2 ). At the DFT level, the antiferromagnetic coupling of the unpaired electrons on the iron centers is favored by 7-8 kJ $\mathrm{mol}^{-1}$ with respect to the ferromagnetic coupling. This result is similar to what previously reported for other open-shell metalbased systems ${ }^{4-46}$ and agrees with the antiferromagnetic nature of ZIF-8 $(\mathrm{Fe})$ verified in the experiments. ${ }^{19}$

For ZIF-8 $(\mathrm{Fe})$, the transition from the ambient pressure phase (IP) to HP would require only $56.8 \mathrm{~kJ} \mathrm{~mol}^{-1}$, that is, only $2.4 \mathrm{~kJ} \mathrm{~mol}^{-1}$ linker ${ }^{-1}$, half that in the magnesium-based ZIF and one-fourth that in the zinc-based ZIF.

The electrostatic potential maps of IP and IP-A conformers of $\mathrm{ZIF}-8(\mathrm{Fe})$ presented in Figures $2 \mathrm{~d}$ and 5a, respectively, show values between those of $\mathrm{Zn}$ and $\mathrm{Mg}$.

The position of ZIF- $8(\mathrm{Zn})$ and ZIF- $8(\mathrm{Mg})$ conduction and valence bands is determined by the orbitals of the mIm linker (see sections 3.1 and 3.2). For ZIF-8(Fe), it is mainly associated with the Fe d-orbitals (see Figure S5), as observed for other MOFs based on open-shell metals. ${ }^{41}$ For this reason, 
the ZIF-8 $(\mathrm{Fe})$ band gap is about half the value of those of ZIF8(Zn) and ZIF-8 $(\mathrm{Mg}$ ) (see Figure 3): $\sim 3.4 \mathrm{eV}$ (see Table 1). An absorption in the near-UV $(3.4 \mathrm{eV} \cong 364 \mathrm{~nm})$, would be responsible for the observed yellow color of this material. ${ }^{19} \mathrm{~A}$ band gap of $3.4 \mathrm{eV}$ makes ZIF-8(Fe) a wide-band-gap semiconductor. Moreover, it is a direct band-gap material, which would make ZIF-8(Fe) an interesting candidate not only for photocatalysis but also for solar cells and photonics, to produce blue lasers and light-emitting diodes (LEDs).

\section{DISCUSSION}

The energy dependence on $\theta$ of ZIF-8(Mg) (blue circles), $\mathrm{ZIF}-8(\mathrm{Zn})$ (gray squares), and ZIF- $8(\mathrm{Fe})$ (magenta diamonds) is shown in Figure $7 \mathrm{a}$. Hobday et al. have previously
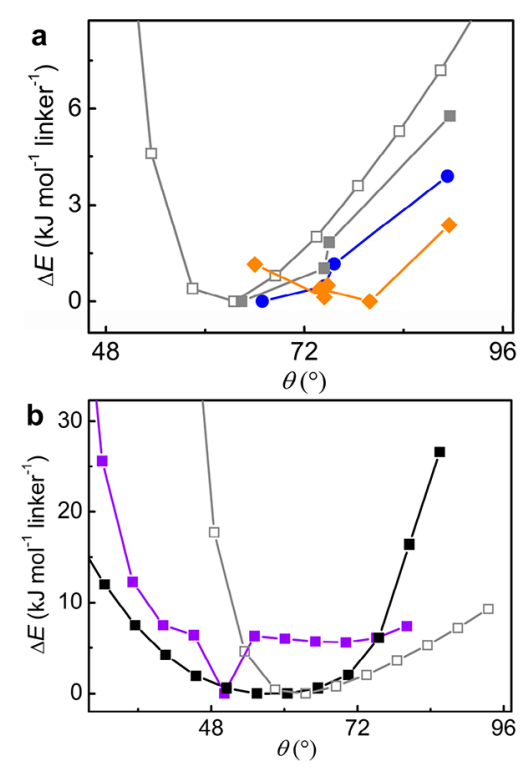

Figure 7. Energy dependence on $\theta$. (a) Data for ZIF- $8(\mathrm{Mg}$ ) (blue circles), ZIF-8(Zn) (gray squares), and ZIF- $8(\mathrm{Fe})$ (orange diamonds, $2 S+1=49$ ) as calculated at the B3LYP-D*/TZV level. ZIF-8 (empty gray squares) data as in ref 7 are also reported for comparison. (b) Literature data on ZIF-8 (empty gray squares), ZIF-90 (black squares), and ZIF-65 (violet squares) obtained by using a plane wave basis set in combination with the Perdew-Burke-Ernzerhof exchange-correlation functional augmented with the TkatchenkoScheffler dispersion correction. ${ }^{7}$ The zero of the energy is set to the energy of the ground state for each system.

studied the influence of the linker functional groups on the gate opening energy in ZIF- 8 materials ${ }^{7}$ using periodic DFT calculations, Grand Canonical Monte Carlo (GCMC), and high-pressure XRD. For the XRD measurements, they have used a 4:1 mixture of methanol:ethanol as pressure-transmitting medium (hydrostatic medium). They used the DFT methods to study the energy required in vacuum to modify $\theta$ in $\mathrm{ZIF}-8(\mathrm{Zn}), \mathrm{ZIF}-65(\mathrm{Zn})\left(\mathrm{Zn}(\mathrm{nIm})_{2}, \mathrm{nIm}=2\right.$-nitroimidazolate), and ZIF-90(Zn) $(\mathrm{Zn}(\mathrm{ICA}))_{2}$, ICA = imidazolate-2-carboxyaldehyde): these data are included in Figure $7 \mathrm{~b}$. Both the DFT and the XRD data pointed out that the functional group has a large influence on the value of $\theta$ in the ground state structure of the ZIFs: $64.3^{\circ}$ for ZIF- $8,66.54^{\circ}$ for ZIF-90, and $46.3^{\circ}$ for ZIF-65. The DFT calculations indicate that in the absence of adsorbates the functionalization of the linker does not influence the cost of a $+20^{\circ}$ rotation of the imidazolate ring, being the same for the three ZIFs (about +6
$\mathrm{kJ} \mathrm{mol}^{-1}$ per linker, see Figure $7 \mathrm{~b}$ ). The scenario changes completely in the presence of guests in the pores, as revealed by the XRD and GCMC data. If methanol is adsorbed in the ZIF pores, it interacts with the functional groups on the linker, changing the sign and the extent of the $\theta$ variation upon pressure: for ZIF- $8, \theta$ increases from its ambient pressure value to $89.7^{\circ}$ at $14700 \mathrm{bar}$, for ZIF-90 to $84.06^{\circ}$ at $19500 \mathrm{bar}$, and for ZIF-65 $\theta$ decreases to $30.87^{\circ}$ at 47700 bar. ${ }^{7}$ The energy required for such rotations is computed to be 7.2, 26.0, and $19.2 \mathrm{~kJ} \mathrm{~mol}^{-1}$ per linker for ZIF-8, ZIF-90, and ZIF-65, respectively. ${ }^{7}$ These changes in $\theta$ correspond to an AP to HP phase transition for ZIF-8 and ZIF-90, while for ZIF-65 a phase transition is not observed. The different behavior of ZIF65 is associated with strong interlinkers interactions due to the $-\mathrm{NO}_{2}$ groups on $\mathrm{mIm}$ and to their interaction with methanol molecules.

In this study, we have used the metal substitution as an alternative strategy to modify the gate opening energy of the ZIFs. The metal substitution presents a significant difference than the linker substitution: it does not introduce the extra interlinker interactions evidenced in ref 7 , and then the dependence of $\theta$ on the pressure is expected to be qualitatively the same as in ZIF- $8(\mathrm{Zn})$. We verify that the substitution of $\mathrm{Zn}$ with $\mathrm{Mg}$ would cause the drop of the energy fee for the AP $\rightarrow$ $\mathrm{HP}$ transition from 5.8 to $3.9 \mathrm{~kJ} \mathrm{~mol}^{-1}$ per linker. For the ironbased material, the ambient pressure phase is an intermediate phase IP. For ZIF-8(Fe), both AP $\rightarrow \mathrm{HP}$ and IP $\rightarrow \mathrm{HP}$ transition would cost only $\sim 2.5 \mathrm{~kJ} \mathrm{~mol}^{-1}$ per linker, the lowest value reported for a ZIF-8 material.

As mentioned above, the performance of ZIF- 8 materials toward separations is mainly determined by the diameter of the $6 \mathrm{MR}$ windows that increases upon $\mathrm{AP} \rightarrow \mathrm{HP}$ and $\mathrm{IP} \rightarrow \mathrm{HP}$ transitions. Such increase is small in absolute terms, but it is enough to affect the separation performance of a material for certain mixtures of small molecules. ${ }^{8,47}$ Considering the kinetic diameter of molecular species present in natural gas, ${ }^{47}$ we can predict $\mathrm{ZIF}-8(\mathrm{Zn})-\mathrm{AP}$ as a suitable sieve for $\mathrm{H}_{2} \mathrm{O}, \mathrm{H}_{2}$, or $\mathrm{He}$ and any of their mixtures (diameter $\leq 3.0 \AA, 6 \mathrm{MR}$ opening) from $\mathrm{CH}_{4}, \mathrm{~N}_{2}, \mathrm{CO}_{2}, \mathrm{CO}$, and $\mathrm{H}_{2} \mathrm{~S}$ (diameter $>3.0 \AA$ ). Among the possible gas mixtures, the most relevant are $\mathrm{H}_{2} / \mathrm{CO}_{2}$ and $\mathrm{H}_{2} / \mathrm{CO}$ for hydrogen production from petrochemicals and in steel plants. In ZIF-8( $\mathrm{Zn})-\mathrm{HP}$, the $6 \mathrm{MR}$ opening is larger than in the AP phase (3.6 vs $3.0 \AA$, see Table 1 ): this phase is a good separator for $\mathrm{CH}_{4}, \mathrm{~N}_{2}$, and $\mathrm{CO}$ from $\mathrm{CO}_{2}, \mathrm{H}_{2} \mathrm{O}, \mathrm{H}_{2} \mathrm{~S}$, $\mathrm{He}$, and $\mathrm{H}_{2}$. The ZIF-8(Zn)-HP phase is more promising for gas separation than the AP phase because it could be used for the industrially relevant separations: $\mathrm{CH}_{4} / \mathrm{CO}_{2}, \mathrm{CO} / \mathrm{CO}_{2}$, $\mathrm{CO}_{2} / \mathrm{N}_{2}$, and $\mathrm{H}_{2} / \mathrm{CO}$. Nevertheless, the low flexibility of ZIF$8(\mathrm{Zn})$ does not make accessible HP phase at pressures typical for these separation processes.

The larger $d(\mathrm{Mg}-\mathrm{N})$ also causes a larger dimension of the $6 \mathrm{MR}$ windows in ZIF-8 $(\mathrm{Mg}$ ) than in ZIF-8( $\mathrm{Zn}$ ) (see Table 1 ). Again, the gases that could be separated by the HP phase are more relevant on the applicative side than those that can be separated by using the AP phase: in fact, ZIF- $8(\mathrm{Mg})-\mathrm{HP}$ is a good separator for $\mathrm{CH}_{4}$ and $\mathrm{CO}$ (diameter $>3.7 \AA$ ) from $\mathrm{CO}_{2}$, $\mathrm{N}_{2}, \mathrm{H}_{2} \mathrm{O}, \mathrm{H}_{2} \mathrm{~S}$, He, and $\mathrm{H}_{2}$. ZIF- $8(\mathrm{Mg})$-HP could be then a material suitable for purifying methane from most common contaminants in natural gas in just one separation step. ZIF$8(\mathrm{Mg})$-HP would be accessible at lower pressures than ZIF$8(\mathrm{Zn})-\mathrm{HP}$ : its gate opening requires only half of the energy (3.9 vs $5.8 \mathrm{~kJ} \mathrm{~mol}^{-1}$ per linker). Future experiment should be 
directed to measure the onset pressure for the AP-to-HP phase transition.

ZIF-8(Fe)-HP has similar pore opening dimensions to those of ZIF-8(Mg)-HP, and it can be employed for the same purposes. Interestingly, for iron, the transition from the ambient pressure phase, IP, to HP would happen at even lower pressures than $\mathrm{Mg}$ : here the gate opening requires only $2.4 \mathrm{~kJ} \mathrm{~mol}^{-1}$ per linker, likely making the HP phase accessible at pressures of practical interest. Actually, NO adsorption in ZIF-8 $(\mathrm{Fe})$ shows a sharp increase in adsorption at 0.2 bar, which can be associated with the IP $\rightarrow$ HP transition, while this is not observed for ZIF-8 $(\mathrm{Zn})$ even at 1 bar. ${ }^{19}$

$\mathrm{ZIF}-8(\mathrm{Zn})$ application in gas storage and catalysis is often limited by its low ionicity. ${ }^{12}$ Electrostatic potential maps in Figure 2 show how the polarity of the structure increases by substituting $\mathrm{Zn}$ with $\mathrm{Fe}$ or $\mathrm{Mg}$. ZIF- $8(\mathrm{Mg})$ shows a large enhancement of the ionicity of the whole structure: in Figure $2 \mathrm{c}$ there are almost no regions with a value close to zero of the electrostatic potential (green color), unlike ZIF-8(Zn) and ZIF-8 $(\mathrm{Fe})$. Besides gas storage, ZIF- $8(\mathrm{Mg})$ is then expected to be a better catalyst candidate for all the reactions catalyzed by ZIF-8(Zn). ${ }^{12,48-51}$ These reactions (e.g., organic carbonate syntheses) do not require the direct involvement of the metal catalyst, but the catalytic sites are likely the imidazole rings. ${ }^{12}$ Otherwise, ZIF-8 $(\mathrm{Fe})$ would allow ZIF-8 materials to catalyze those reactions that require the direct involvement of the metal and that have not been explored so far for ZIF-8 materials. Moreover, its band gap of only $3.4 \mathrm{eV}$ makes it a potentially promising material for photocatalysis (in analogy to other iron based systems $)^{52-55}$ and for photonic applications.

Unfortunately, a larger structure polarity corresponds often to a lower air stability, mainly associated with an increased reactivity toward water. ${ }^{43,56}$ For both ZIF- $8(\mathrm{Mg})$ and ZIF$8(\mathrm{Fe})$, in fact, the only two studies existing report about a large air instability of these materials, mainly associated with moisture. ${ }^{18,19}$ For ZIF-8 $(\mathrm{Mg})$, this is likely a direct consequence of the material properties, restricting its application to dry conditions. The synthesis reported for ZIF- $8(\mathrm{Fe})$ is instead far to be optimized, and the material reported contains a large concentration of defects ${ }^{19}$ that could be the reason for its instability, catalyzing the reaction with water. $^{56} \mathrm{New}$ efforts directed to the synthesis of a defect-free ZIF-8 $(\mathrm{Fe})$ would be beneficial not only to improve the properties of the material itself but also to enlarge the range of conditions in which ZIF-8 $(\mathrm{Fe})$ could be applied.

\section{CONCLUSIONS}

We have shown by using computations that metal substitution is a very effective way to tune the flexibility of ZIF- 8 materials. For both the magnesium- and iron-based systems the gate opening phenomenon requires half and a fourth of the energy for the zinc material, respectively. ${ }^{7}$ Because of the importance of ZIF-8 among porous materials and because the AP-to-HP phase transition is its most studied property, our results strongly call for future diffraction studies in pressure aimed at the experimental verification of the present findings.

\section{ASSOCIATED CONTENT}

\section{SI Supporting Information}

The Supporting Information is available free of charge at https://pubs.acs.org/doi/10.1021/acs.chemmater.1c00623.
Density of states plot for all the ZIFs, electronic band structure of all the ZIFs, and supplementary data for multireference calculations (PDF)

CIF files for all the optimized structures (ZIP)

\section{AUTHOR INFORMATION}

\section{Corresponding Author}

Jenny G. Vitillo - Department of Science and High

Technology and INSTM, University of Insubria, 22100

Como, Italy; Department of Chemistry, Chemical Theory

Center, and Supercomputing Institute, University of

Minnesota, Minneapolis, Minnesota 55455-0431, United

States; (1) orcid.org/0000-0002-6213-2039;

Email: jg.vitillo@gmail.com

\section{Author}

Laura Gagliardi - Department of Chemistry, Pritzker School of Molecular Engineering, James Franck Institute, University of Chicago, Chicago, Illinois 60637, United States;

(1) orcid.org/0000-0001-5227-1396

Complete contact information is available at:

https://pubs.acs.org/10.1021/acs.chemmater.1c00623

\section{Notes}

The authors declare no competing financial interest.

\section{ACKNOWLEDGMENTS}

This work was supported by the Inorganometallic Catalyst Design Center, an EFRC funded by the DOE, Office of Basic Energy Sciences (DE-SC0012702). The authors acknowledge the Minnesota Supercomputing Institute (MSI) at the University of Minnesota for providing computational resources.

\section{ABBREVIATIONS}

ZIF, zeolitic imidazolate frameworks; DFT, density functional theory; MUV, Materials of University of Valencia; Im, imidazolate; mIm, methylimidazolate; MOF, metal-organic framework; AP, IP, and HP refer to ZIF-8 structures having the angle between the plane of the imidazolate rings and the fourmember ring of $\sim 65^{\circ}, \sim 75^{\circ}$, and $\sim 85^{\circ}$, respectively; $\mathrm{MR}$, membered ring.

\section{REFERENCES}

(1) Phan, A.; Doonan, C. J.; Uribe-Romo, F. J.; Knobler, C. B.; O'Keeffe, M.; Yaghi, O. M. Synthesis, Structure, and Carbon Dioxide Capture Properties of Zeolitic Imidazolate Frameworks. Acc. Chem. Res. 2010, 43 (1), 58-67.

(2) Zhang, J.-P.; Zhang, Y.-B.; Lin, J.-B.; Chen, X.-M. Metal Azolate Frameworks: From Crystal Engineering to Functional Materials. Chem. Rev. 2012, 112 (2), 1001-1033.

(3) Park, K. S.; Ni, Z.; Côté, A. P.; Choi, J. Y.; Huang, R.; UribeRomo, F. J.; Chae, H. K.; O’Keeffe, M.; Yaghi, O. M. Exceptional chemical and thermal stability of zeolitic imidazolate frameworks. Proc. Natl. Acad. Sci. U. S. A. 2006, 103 (27), 10186.

(4) Ethiraj, J.; Bonino, F.; Lamberti, C.; Bordiga, S. $\mathrm{H}_{2} \mathrm{~S}$ interaction with HKUST-1 and ZIF-8 MOFs: A multitechnique study. Microporous Mesoporous Mater. 2015, 207, 90-94.

(5) Zhao, P.; Bennett, T. D.; Casati, N. P. M.; Lampronti, G. I.; Moggach, S. A.; Redfern, S. A. T. Pressure-induced oversaturation and phase transition in zeolitic imidazolate frameworks with remarkable mechanical stability. Dalton Trans. 2015, 44 (10), 4498-4503.

(6) Zhang, W.; Maul, J.; Vulpe, D.; Moghadam, P. Z.; FairenJimenez, D.; Mittleman, D. M.; Zeitler, J. A.; Erba, A.; Ruggiero, M. T. 
Probing the Mechanochemistry of Metal-Organic Frameworks with Low-Frequency Vibrational Spectroscopy. J. Phys. Chem. C 2018, 122 (48), 27442-27450.

(7) Hobday, C. L.; Bennett, T. D.; Fairen-Jimenez, D.; Graham, A. J.; Morrison, C. A.; Allan, D. R.; Düren, T.; Moggach, S. A. Tuning the Swing Effect by Chemical Functionalization of Zeolitic Imidazolate Frameworks. J. Am. Chem. Soc. 2018, 140 (1), 382-387.

(8) Hobday, C. L.; Woodall, C. H.; Lennox, M. J.; Frost, M.; Kamenev, K.; Düren, T.; Morrison, C. A.; Moggach, S. A. Understanding the adsorption process in ZIF-8 using high pressure crystallography and computational modelling. Nat. Commun. 2018, 9 (1), 1429.

(9) Zhang, K.; Lively, R. P.; Dose, M. E.; Brown, A. J.; Zhang, C.; Chung, J.; Nair, S.; Koros, W. J.; Chance, R. R. Alcohol and water adsorption in zeolitic imidazolate frameworks. Chem. Commun. 2013, 49 (31), 3245-3247.

(10) Sumida, K.; Rogow, D. L.; Mason, J. A.; McDonald, T. M.; Bloch, E. D.; Herm, Z. R.; Bae, T.-H.; Long, J. R. Carbon Dioxide Capture in Metal-Organic Frameworks. Chem. Rev. 2012, 112 (2), 724-781.

(11) Chaemchuen, S.; Xiao, X.; Ghadamyari, M.; Mousavi, B.; Klomkliang, N.; Yuan, Y.; Verpoort, F. Robust and efficient catalyst derived from bimetallic $\mathrm{Zn} / \mathrm{Co}$ zeolitic imidazolate frameworks for $\mathrm{CO}_{2}$ conversion. J. Catal. 2019, 370, 38-45.

(12) Vitillo, J. G.; Crocellà, V.; Bonino, F. ZIF-8 as a Catalyst in Ethylene Oxide and Propylene Oxide Reaction with $\mathrm{CO}_{2}$ to Cyclic Organic Carbonates. ChemEngineering 2019, 3 (3), 60.

(13) Zhu, M.; Venna, S. R.; Jasinski, J. B.; Carreon, M. A. RoomTemperature Synthesis of ZIF-8: The Coexistence of ZnO Nanoneedles. Chem. Mater. 2011, 23 (16), 3590-3592.

(14) Moggach, S. A.; Bennett, T. D.; Cheetham, A. K. The Effect of Pressure on ZIF-8: Increasing Pore Size with Pressure and the Formation of a High-Pressure Phase at 1.47 GPa. Angew. Chem., Int. Ed. 2009, 48 (38), 7087-7089.

(15) Fairen-Jimenez, D.; Moggach, S. A.; Wharmby, M. T.; Wright, P. A.; Parsons, S.; Duren, T. Opening the Gate: Framework Flexibility in ZIF-8 Explored by Experiments and Simulations. J. Am. Chem. Soc. 2011, 133 (23), 8900-8902.

(16) Maul, J.; Ryder, M. R.; Ruggiero, M. T.; Erba, A. Pressuredriven mechanical anisotropy and destabilization in zeolitic imidazolate frameworks. Phys. Rev. B: Condens. Matter Mater. Phys. 2019, 99 (1), 014102.

(17) Tian, T.; Wharmby, M. T.; Parra, J. B.; Ania, C. O.; FairenJimenez, D. Role of crystal size on swing-effect and adsorption induced structure transition of ZIF-8. Dalton Trans. 2016, 45 (16), 6893-6900.

(18) Horike, S.; Kadota, K.; Itakura, T.; Inukai, M.; Kitagawa, S. Synthesis of magnesium ZIF-8 from $\mathrm{Mg}\left(\mathrm{BH}_{4}\right)_{2}$. Dalton Trans. 2015, 44 (34), 15107-15110.

(19) López-Cabrelles, J.; Romero, J.; Abellán, G.; Giménez-Marqués, M.; Palomino, M.; Valencia, S.; Rey, F.; Mínguez Espallargas, G. Solvent-Free Synthesis of ZIFs: A Route toward the Elusive $\mathrm{Fe}(\mathrm{II})$ Analogue of ZIF-8. J. Am. Chem. Soc. 2019, 141 (17), 7173-7180.

(20) Dovesi, R.; Erba, A.; Orlando, R.; Zicovich-Wilson, C. M.; Civalleri, B.; Maschio, L.; Rérat, M.; Casassa, S.; Baima, J.; Salustro, S.; Kirtman, B. Quantum-mechanical condensed matter simulations with CRYSTAL. WIREs Comput. Mol. Sci. 2018, 8 (4), e1360.

(21) Becke, A. D. Density-Functional Thermochemistry 3. The Role of Exact Exchange. J. Chem. Phys. 1993, 98 (7), 5648-5652.

(22) Lee, C.; Yang, W.; Parr, R. G. Development of the ColleSalvetti Correlation-Energy Formula Into a Functional of the Electron Density. Phys. Rev. B: Condens. Matter Mater. Phys. 1988, 37, 785789.

(23) Grimme, S. Semiempirical GGA-type density functional constructed with a long-range dispersion correction. J. Comput. Chem. 2006, 27 (15), 1787-1799.

(24) Civalleri, B.; Zicovich-Wilson, C. M.; Valenzano, L.; Ugliengo, P. B3LYP augmented with an empirical dispersion term (B3LYP-D*) as applied to molecular crystals. CrystEngComm 2008, 10 (4), 405410.

(25) Zhao, Y.; Truhlar, D. G. Computational characterization and modeling of buckyball tweezers: density functional study of concaveconvex $\pi \cdots \pi$ interactions. Phys. Chem. Chem. Phys. 2008, 10 (19), 2813-2818.

(26) Peintinger, M. F.; Oliveira, D. V.; Bredow, T. Consistent Gaussian basis sets of triple-zeta valence with polarization quality for solid-state calculations. J. Comput. Chem. 2013, 34 (6), 451-459.

(27) Schäfer, A.; Horn, H.; Ahlrichs, R. Fully optimized contracted Gaussian basis sets for atoms Li to Kr. J. Chem. Phys. 1992, 97 (4), 2571-2577.

(28) Valenzano, L.; Civalleri, B.; Chavan, S.; Turnes Palomino, G.; Otero Arean, C.; Bordiga, S. Computational and Experimental Studies on the Adsorption of $\mathrm{CO}, \mathrm{N}_{2}$, and $\mathrm{CO}_{2}$ on Mg-MOF-74. J. Phys. Chem. C 2010, 114 (25), 11185-11191.

(29) Dovesi, R.; Orlando, R.; Erba, A.; Zicovich-Wilson, C. M.; Civalleri, B.; Casassa, S.; Maschio, L.; Ferrabone, M.; De La Pierre, M.; D'Arco, P.; Noel, Y.; Causa, M.; Rerat, M.; Kirtman, B. CRYSTAL14: A Program for the Ab Initio Investigation of Crystalline Solids. Int. J. Quantum Chem. 2014, 114 (19), 1287-1317.

(30) Broyden, C. G. A class of methods for solving nonlinear simultaneous equations. Math. Comput. 1965, 19, 577-593.

(31) Johnson, D. D. Modified Broyden's method for accelerating convergence in self-consistent calculations. Phys. Rev. B: Condens. Matter Mater. Phys. 1988, 38 (18), 12807-12813.

(32) Beata, G.; Perego, G.; Civalleri, B. CRYSPLOT: A new tool to visualize physical and chemical properties of molecules, polymers, surfaces, and crystalline solids. J. Comput. Chem. 2019, 40 (26), 2329-2338.

(33) Canepa, P.; Hanson, R. M.; Ugliengo, P.; Alfredsson, M. J-ICE: a new Jmol interface for handling and visualizing crystallographic and electronic properties. J. Appl. Crystallogr. 2011, 44 (1), 225-229.

(34) Frisch, M. J.; Trucks, G. W.; Schlegel, H. B.; Scuseria, G. E.; Robb, M. A.; Cheeseman, J. R.; Scalmani, G.; Barone, V.; Petersson, G. A.; Nakatsuji, H.; Li, X.; Caricato, M.; Marenich, A. V.; Bloino, J.; Janesko, B. G.; Gomperts, R.; Mennucci, B.; Hratchian, H. P.; Ortiz, J. V.; Izmaylov, A. F.; Sonnenberg, J. L.; Williams; Ding, F.; Lipparini, F.; Egidi, F.; Goings, J.; Peng, B.; Petrone, A.; Henderson, T.; Ranasinghe, D.; Zakrzewski, V. G.; Gao, J.; Rega, N.; Zheng, G.; Liang, W.; Hada, M.; Ehara, M.; Toyota, K.; Fukuda, R.; Hasegawa, J.; Ishida, M.; Nakajima, T.; Honda, Y.; Kitao, O.; Nakai, H.; Vreven, T.; Throssell, K.; Montgomery, Jr., J. A.; Peralta, J. E.; Ogliaro, F.; Bearpark, M. J.; Heyd, J. J.; Brothers, E. N.; Kudin, K. N.; Staroverov, V. N.; Keith, T. A.; Kobayashi, R.; Normand, J.; Raghavachari, K.; Rendell, A. P.; Burant, J. C.; Iyengar, S. S.; Tomasi, J.; Cossi, M.; Millam, J. M.; Klene, M.; Adamo, C.; Cammi, R.; Ochterski, J. W.; Martin, R. L.; Morokuma, K.; Farkas, O.; Foresman, J. B.; Fox, D. J. Gaussian 16, Rev. B.01; Gaussian Inc.: Wallingford, CT, 2016.

(35) Roos, B. O.; Lawley, K. P. The Complete Active Space SelfConsistent Field Method and its Applications in Electronic Structure Calculations. Adv. Chem. Phys. 2007, 69, 399-445.

(36) Andersson, K.; Malmqvist, P. A.; Roos, B. O.; Sadlej, A. J.; Wolinski, K. Second-order perturbation theory with a CASSCF reference function. J. Phys. Chem. 1990, 94 (14), 5483-5488.

(37) Aquilante, F.; Autschbach, J.; Carlson, R. K.; Chibotaru, L. F.; Delcey, M. G.; De Vico, L.; Fdez. Galván, I.; Ferré, N.; Frutos, L. M.; Gagliardi, L.; Garavelli, M.; Giussani, A.; Hoyer, C. E.; Li Manni, G.; Lischka, H.; Ma, D.; Malmqvist, P. Å.; Müller, T.; Nenov, A.; Olivucci, M.; Pedersen, T. B.; Peng, D.; Plasser, F.; Pritchard, B.; Reiher, M.; Rivalta, I.; Schapiro, I.; Segarra-Martí, J.; Stenrup, M.; Truhlar, D. G.; Ungur, L.; Valentini, A.; Vancoillie, S.; Veryazov, V.; Vysotskiy, V. P.; Weingart, O.; Zapata, F.; Lindh, R. Molcas 8: New capabilities for multiconfigurational quantum chemical calculations across the periodic table. J. Comput. Chem. 2016, 37 (5), 506-541.

(38) Roos, B. O.; Lindh, R.; Malmqvist, P.-Å.; Veryazov, V.; Widmark, P.-O. New Relativistic ANO Basis Sets for Transition Metal Atoms. J. Phys. Chem. A 2005, 109 (29), 6575-6579. 
(39) Roos, B. O.; Lindh, R.; Malmqvist, P.-Å.; Veryazov, V.; Widmark, P.-O. Main Group Atoms and Dimers Studied with a New Relativistic ANO Basis Set. J. Phys. Chem. A 2004, 108 (15), 28512858.

(40) Aquilante, F.; Pedersen, T. B.; Lindh, R. Low-cost evaluation of the exchange Fock matrix from Cholesky and density fitting representations of the electron repulsion integrals. J. Chem. Phys. 2007, 126 (19), 194106.

(41) Ryder, M. R.; Donà, L.; Vitillo, J. G.; Civalleri, B. Understanding and Controlling the Dielectric Response of MetalOrganic Frameworks. ChemPlusChem 2018, 83 (4), 308-316.

(42) Macrae, C. F.; Sovago, I.; Cottrell, S. J.; Galek, P. T. A.; McCabe, P.; Pidcock, E.; Platings, M.; Shields, G. P.; Stevens, J. S.; Towler, M.; Wood, P. A. Mercury 4.0: from visualization to analysis, design and prediction. J. Appl. Crystallogr. 2020, 53 (1), 226-235.

(43) Vitillo, J. G. Magnesium-based systems for carbon dioxide capture, storage and recycling: from leaves to synthetic nanostructured materials. RSC Adv. 2015, 5 (46), 36192-36239.

(44) Vitillo, J. G.; Bhan, A.; Cramer, C. J.; Lu, C. C.; Gagliardi, L. Quantum Chemical Characterization of Structural Single Fe(II) Sites in MIL-Type Metal-Organic Frameworks for the Oxidation of Methane to Methanol and Ethane to Ethanol. ACS Catal. 2019, 9 (4), $2870-2879$

(45) Oktawiec, J.; Jiang, H. Z. H.; Vitillo, J. G.; Reed, D. A.; Darago, L. E.; Trump, B. A.; Bernales, V.; Li, H.; Colwell, K. A.; Furukawa, H.; Brown, C. M.; Gagliardi, L.; Long, J. R. Negative cooperativity upon hydrogen bond-stabilized $\mathrm{O}_{2}$ adsorption in a redox-active metalorganic framework. Nat. Commun. 2020, 11 (1), 3087.

(46) D’Amore, M.; Civalleri, B.; Bush, I. J.; Albanese, E.; Ferrabone, M. Elucidating the Interaction of $\mathrm{CO}_{2}$ in the Giant Metal-Organic Framework MIL-100 through Large-Scale Periodic Ab Initio Modeling. J. Phys. Chem. C 2019, 123 (47), 28677-28687.

(47) Tagliabue, M.; Farrusseng, D.; Valencia, S.; Aguado, S.; Ravon, U.; Rizzo, C.; Corma, A.; Mirodatos, C. Natural gas treating by selective adsorption: Material science and chemical engineering interplay. Chem. Eng. J. 2009, 155 (3), 553-566.

(48) Wee, L. H.; Lescouet, T.; Ethiraj, J.; Bonino, F.; Vidruk, R.; Garrier, E.; Packet, D.; Bordiga, S.; Farrusseng, D.; Herskowitz, M.; Martens, J. A. Hierarchical Zeolitic Imidazolate Framework-8 Catalyst for Monoglyceride Synthesis. ChemCatChem 2013, 5 (12), 35623566.

(49) Yin, H.; Kim, H.; Choi, J.; Yip, A. C. K. Thermal stability of ZIF-8 under oxidative and inert environments: A practical perspective on using ZIF-8 as a catalyst support. Chem. Eng. J. 2015, 278, 293300.

(50) Beyzavi, M. H.; Stephenson, C. J.; Liu, Y.; Karagiaridi, O.; Hupp, J. T.; Farha, O. K. Metal-Organic Framework-Based Catalysts: Chemical Fixation of $\mathrm{CO}_{2}$ with Epoxides Leading to Cyclic Organic Carbonates. Front. Energy Res. 2015, 2, 63.

(51) Tran, U. P. N.; Le, K. K. A.; Phan, N. T. S. Expanding Applications of Metal-Organic Frameworks: Zeolite Imidazolate Framework ZIF-8 as an Efficient Heterogeneous Catalyst for the Knoevenagel Reaction. ACS Catal. 2011, 1 (2), 120-127.

(52) Chen, H.; Liu, Y.; Cai, T.; Dong, W.; Tang, L.; Xia, X.; Wang, L.; Li, T. Boosting Photocatalytic Performance in Mixed-Valence MIL-53(Fe) by Changing FeII/FeIII Ratio. ACS Appl. Mater. Interfaces 2019, 11 (32), 28791-28800.

(53) Chen, Y.; Wang, D.; Deng, X.; Li, Z. Metal-organic frameworks (MOFs) for photocatalytic $\mathrm{CO}_{2}$ reduction. Catal. Sci. Technol. 2017, 7 (21), 4893-4904.

(54) Guesh, K.; Caiuby, C. A. D.; Mayoral, Á.; Díaz-García, M.; Díaz, I.; Sanchez-Sanchez, M. Sustainable Preparation of MIL$100(\mathrm{Fe})$ and Its Photocatalytic Behavior in the Degradation of Methyl Orange in Water. Cryst. Growth Des. 2017, 17 (4), 18061813.

(55) Wang, D.; Wang, M.; Li, Z. Fe-Based Metal-Organic Frameworks for Highly Selective Photocatalytic Benzene Hydroxylation to Phenol. ACS Catal. 2015, 5 (11), 6852-6857.
(56) Vitillo, J. G.; Bordiga, S. Increasing the stability of $\mathrm{Mg}_{2}$ (dobpdc) metal-organic framework in air through solvent removal. Mater. Chem. Front. 2017, 1 (3), 444-448. 